\title{
Newer Methods of Nanoparticle Synthesis: Nitroimidazole properties with Nanometal oxides in Polymer Cages as Drug-Biomarker Monitors.
}

\author{
R.Sharma* \\ *Center of Nanomagnetics and Biotechnology, Florida State University,
} Tallahassee, Florida 32310.

\begin{abstract}
Nitroimidazoles are radiosensitizers and hypoxia detecting chemosensitizers. Intially nitroimidazoles were single dose antibiotic drugs. Recently, nitroimidazole derivatives have emerged as multifunctional "drug-biomarker monitors" chemical compounds with importance in treatment of tumors, monitoring hypoxia and safer imaging contrast agents to monitor the therapeutic progress. Additionally, the number of nitroimidazole derivatives is growing and identified their importance as multifunctional nanoparticles. The nanoparticle synthesis scheme of nitroimidazole was proposed as nitroimidazole caged with metal oxide inside polymer coating and labeled with marker biomolecules. We report the step by step user-friendly new co-precipitation schemes of nitroimidazole carrier nanoparticles with their mechanisms of drug controlled release behavior, metal oxide sensitivity to imaging modalities and polymer coating chemistry developed at our lab. The multifunctional nitroimidazole nanoparticles were useful in detection and monitoring of hypoxia, cancer chemotherapy and soft tissue infections. In conclusion, nitroimidazoles are potential multifunctional molecules useful in chemotherapy, antiparasitic and monitoring hypoxia with greater possibility of simultaneous use of radiolabeled 2'nitroimidazoles as radiosensitizers, MRI-PET-US contrast imaging agents.
\end{abstract}

Key words: nitroimidazole, radiosensitizers, imaging agent, antiparasitic, MRI-PET

\section{INTRODUCTION}

2'nitroimidazole compounds and analogs are becoming state of art radiosensitizers and chemosensitizers in cancer prevention and management. Apart from their newly discovered antitumor properties 2' nitroimidazoles had been proven antiparasitic drugs. However, their toxicity was remained a major issue as they showed strong DNA breaking properties by direct DNA binding and coupling with DNA strands and it caused skepticism of nitroimidazole acceptability as safe choice of noncancer therapeutic value. The binding of nitroimidazole with polymer depends on its hydrophilic bonds over its molecules as shown in Figure 1.

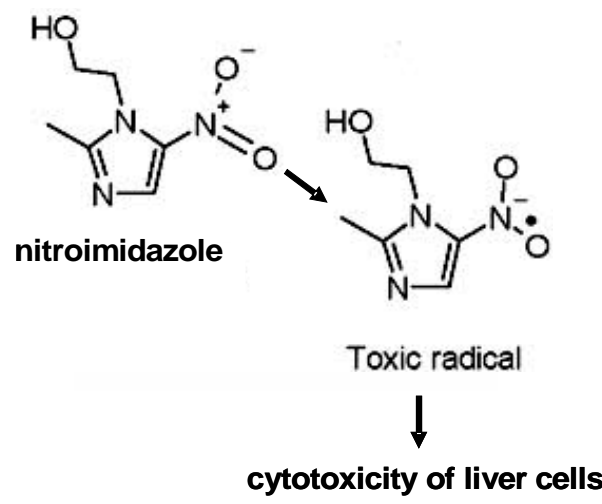

Figure 1: The structure of 2'nitroimidazole is shown with active hydrophilic groups to bind with polyethylene

2 SYNTHESIS OF NITROIMIDAZOLE POLYMER COMPLEXES 


\subsection{The synthesis of nitroimidazole polymer complexes}

The coprecipitation methods were used in our center since the inception of innovative development at center of nanomagnetics and biotechnology using Bang's manual initially and over years the technology was modified for different nanoparticles for various purposes [1]. Mainly the coprecipitation method includes the general steps of: 1. A batch process to develop and prepare the composite particles. A $0.05 \%$ w/w; $10 \mathrm{ml}$ solution of polyethylene wax (number average $\mathrm{MW}$ of 700 g/mole (Honeywell Corp.) using decaline or octamethylcyclotetrasiloxane OMCTS (Dow Chemical Company) at $150^{\circ} \mathrm{C} ; 2$. To this solution, iron oxide powder is added with $30 \%-50 \% \mathrm{w} / \mathrm{w}$ polyethylene, and sonicated at $50 \%$ amplitude for 30 seconds; 3. Then, $10 \mathrm{ml}$ of tetraglyme ("TG") (obtained from Sigma-Aldrich) is added to the ironoxide polyethylene mixture at $150^{\circ} \mathrm{C}$, and sonicated at $50 \%$ amplitude for about 30 seconds; 4.Next, the mixture is immediately cooled to about $0^{\circ} \mathrm{C}$ in ice water held at $0^{\circ} \mathrm{C}$. Within three to four minutes, the polyethylene-iron-oxide mixture is transformed into an emulsion with microdroplets made of supercooled polyethylene wax solution and iron oxide dispersed in a continuous phase of nonsolvent; 5 . The emulsion is warmed to room temperature $27^{\circ} \mathrm{C}$ for 45 minutes to make polyethylene and maghemite particles suspended in the emulsion. This emulsion is cooled to $-10^{\circ} \mathrm{C}$ for half an hour to form a macrophase separated system made of thin reddish-brown sandwiched between top solvent layer and nonsolvent bottom layer; 6 . The reddish-brown layer of polyethylene/iron oxide particles is centrifuged to isolate the particles from solvent mixture. This general strategy was used at our center over several years as described elsewhere [1].

\subsection{Other synthesis methods of polymer nitroimidazole complexes}

\subsubsection{Different polymers used for nitroimidazole}

Chitosan hydrogel beads were prepared by the crosslinking method followed by enteric coating [3]. A CP-A film consisting of a chitosan top layer and sodium alginate sublayer was synthesized and separated by an ornidazole(nitroimidazole)incorporated poly(vinyl alcohol) layer [4]. The xanthan gum, pectin, carrageenan, beta-cyclodextrin (CD) or methacrylic acid-g-guar (MAA-g-GG) gum were used to coat nitroimidazole to design complexes [6]. The branched poly(ethylene glycol) of 5,000, 10,000 and 20,000 Daltons size were used for ester linkage between polymer and nitroimidazole to make complexes [9]. The calcium pectinate coating of nitroimidazole offered as ideal drug carrier [10].

\subsubsection{The nitroimidazole release across polymer cage}

For measurements of controlled etanidazole drug release, triplicate polymer discs were incubated for known intervals in $2 \mathrm{ml} 0.1$ phosphate-buffered saline, $\mathrm{pH}$ 7.4, 37 degrees $\mathrm{C}$ [23]. The method offered a cumulative percentage of the loaded drug that appeared in these serial supernatant fractions was plotted vs. time.

The percentage of the drug that was loaded into each polymer and that was released vs. time was fit to the power function of the form $y=(a) x t b$, where $\mathrm{y}$ is the cumulative released agent, $\mathrm{a}$ and $\mathrm{b}$ are constants and $\mathrm{t}$ is time (days).

\section{DISCUSSION}

The polymer bound nitroimidazoles compounds such as metronidazoles, etanidazoles, tinidazoles have been found useful as hypoxia markers in tumors [5, 18, 23]. Nitroimidazole polymer complexes as hydrogels, beads used as colon targeted drug delivery systems is emerging $[1,3,6,11,13,14,15,17,22]$. Different polymers such as polyethylene glycol [9,20], poly vinyl alcohol [4,24], polymethylmethacrylate[16], polysaccharides[6,11].

Other uses of nitroimidazole polymer complexes as delivery systems are reported in periodontal diseases $[2,21]$, amebiasis [6, 13, 22], helicobector pylori [7], 
gentamycin [16], vaginitis [8], gastritis [10, 12], sprays [19], liposomes [25].

The microbes have been reported as potential coating to carry and transport nitroimidazoles encaged in polymers. Of mention, gentamycin, helicobector pylori and amoeba microbes have been found as potential candidates as targeted nitroimidazole delivery[7, 16, 22]. Other options of liposomes as nitroimidazole delivery systems have been reported as minicapsular extrusion system [25].

The technique of using non-pathogenic bacteria such as Salmonella is an innovative approach in tumor as they replicate and exceed 1000-fold their concentration in tumor. Salmonella typhimurium strains accumulate at tumor sites and serve as carriers for drug bound contrast agents. The bacterial delivery system may serve to transport with nitroimidazole or chemosensitive drugs to the tumor site. Salmonella BR 509 (rod shaped with 1 micron in length) incubated with drug-bound polymer complex may be developed as tumor targeting systems. Our nitroimidazole transport experiments suggested that small size of $\mathrm{Mn}^{+}$particles were diffused into the Entamoeba histolytica cell membrane [26]. The liver cells (Kupffer cells) engulfed the iron oxide bound nitroimidazole in cultures and suggested that iron can function as contrast agent for imaging such as magnetic resonance imaging. The use of attenuated Salmonella typhimurium BRD509 in targeting of drug-coated MNP-loaded Salmonella organisms to tumor sites was reported in administration of the anticancer drug as it would significantly reduce the toxicity associated with prolonged treatment with high doses of chemotherapeutic drugs [27]. The dextrans dicarboxylic acid hemiester conjugates serve as potent prodrugs for nitroimidazole drug release in liver. The release kinetics was dependent on time [28].

\section{CONCLUSION}

The nitroimidazoles are potent radiosensitizers, and are well accepted antiparasitic compounds. Their slow release across colon and tumor is a challenge due to their cytotoxicity caused by their DNA binding properties.

\section{REFERENCES}

1. Kumar P, Singh S, Mishra B. Chem Pharm Bull (Tokyo). 2008;56(9):1234-42.

2. El-Kamel AH, Ashri LY, Alsarra IA. AAPS PharmSciTech. 2007;8(3):E75.

3. Jain SK, Jain A, Gupta Y, Ahirwar M.AAPS PharmSciTech. 2007;8(3):E56.

4. Pei HN, Chen XG, Li Y, Zhou HY.J Biomed Mater Res A. 2008;85(2):566-72.

5. Jin C, Bai L, Wu H, Tian F, Guo G. Biomaterials. 2007;28(25):3724-30.

6. Mundargi RC, Patil SA, Agnihotri SA et al Drug Dev Ind Pharm. 2007;33(3):255-64.

7. Ishak RA, Awad GA, Mortada ND, Nour SA.J Control Release. 2007 Jun 4;119(2):207-14.

8. Baloğlu E, Ozyazici M, et al. Pharm Dev Technol. 2006;11(4):477-84.

9. Bersani C, Berna M, Pasut G, Veronese FM.Farmaco. 2005;60(9):783-8.

10. Sriamornsak P, Thirawong N, Puttipipatkhachorn S.Eur J Pharm Sci. 2005;24(4):363-73.

11. Sinha VR, Kumria R.Drug Dev Ind Pharm. 2004;30(2):143-50.

12. Musiał W, Kubis A.Polim Med. 2003;33(4):29-42.

13. Krishnaiah YS, Muzib YI, Bhaskar P, Satyanarayana V, Latha K.Drug Deliv. 2003;10(4):263-8.

14. Qi M, Wang $\mathrm{P}$, Wu D.Drug Dev Ind Pharm. 2003;29(6):661-7.

15. Krishnaiah YS, Indira Muzib Y, Bhaskar P.J Drug Target. 2003;11(2):109-15.

16. Ramos JR, Howard RD, Pleasant RS, Moll HD, Blodgett DJ, Magnin G, Inzana TJ.Vet Surg. 2003;32(3):251-61.

17. Krishnaiah YS, Muzib YI, Rao GS, Bhaskar P, Satyanarayana V.Drug Deliv. 2003;10(2):111-7. 
18. Tan WH, Lee T, Wang CH.J Pharm Sci. 2003;92(4):773-89.

19. Wang FJ, Wang $\mathrm{CH}$.

20. Wang F, Lee T, Wang CH.Biomaterials. 2002;23(17):3555-66.

21. Varshosaz J, Tavakoli N, Saidian S.Drug Deliv. 2002;9(2):127-33.

22. Krishnaiah YS, Bhaskar Reddy PR, Satyanarayana V, Karthikeyan RS.Int J Pharm. 2002;236(1-2):43-55.

23. Yuan X, Fahlman C, Tabassi K, Williams JA.Cancer Biother Radiopharm. 1999;14(3):177-86.

24. Mallapragada SK, Peppas NA, Colombo P.J Biomed Mater Res. 1997;36(1):125-30.

25. Singh R, Vyas SP.J Drug Target.1997;4(5):26570.

26. Sharma R 1995. Ph.D dissertation: Chap 4 at IIT Delhi.

27. Haik Y et al. 2008. Nature Precedings.

28. Larsen C, Kurtzhals P, Johansen M. Acta Pharm Suec. 1988;25(1):1-14. 